ARTICLE

Received 31 Dec 2015 | Accepted 11 Mar 2016 | Published 19 Apr 2016

\title{
Queer art in Vietnam: from closet to pride in two decades
}

\author{
Cristina Nualart ${ }^{1}$
}

\begin{abstract}
Male and female artists in Vietnam from the early 1990s to the new millennium have contributed art that gives visibility to non-normative lifestyles that go against the traditional values espoused by national rhetoric. This article explores some of the first manifestations of queer art in contemporary Vietnam, outlining a short history of artworks that may be considered "queer" because of their subject matter, irrespective of whether they were made by straight or queer identified artists. Many of these artworks are not made in traditional media, or they break conventions in the local artistic canon. Frequently they have performative characteristics, an art form that arose in Vietnam in the 1990s, the beginning of the timeframe explored here. Photography, another medium not long or firmly established, is also extensively employed. The narrative attends specifically to the dissidence, in content or format, of selected artworks, and points to a correlation over time to an increased tolerance of homosexuality. This article is published as part of a thematic collection on gender studies.
\end{abstract}

\footnotetext{
${ }^{1}$ Department of Art History (Contemporary Art), Universidad Complutense de Madrid, Madrid, Spain
} 


\section{Background}

lthough in Sliwinska's opinion "queer culture is entwined with art and visual culture", research on queer $\operatorname{art}^{1}$ is still scarce (Sliwinska, 2013: 809). In one of the few books that overview the intersection of both topics, Art and Homosexuality, Reed (2011) examines a broad span of artworks and artists from around the world, sometimes going back millennia, to discuss the changing nature of ideas about homosexuality and its acceptance in the various societies he researches. His dissection of geographical and historical contexts bolsters his theories on the meaning and relevance of the selected artworks.

Reed's expansive text includes some commentary on Japan and Polynesia, but offers no accounts from Southeast Asia. This research gap was addressed by curator Lenzi in her paper "How Queer Translates in Southeast Asian Contemporary Art" (2015), a nuanced application of queer analysis to a number of artworks that often do not explicitly reference homosexuality-if they refer to it at all. Lenzi explores both the paradigms of queerness in the region, as well as the question of how art made locally by openly queer artists can operate to some degree as an act of protest from societies under autocratic rule. In non-normative artistic creations she finds striking examples of acts of resistance, which subtly mask sociopolitical topics that cannot be overtly discussed in their country of origin. As stated by the author, the paper makes the general assumption "that art by queer regional artists is generally contestative" (Lenzi, 2015: 12), and although the findings support such a conclusion in that enriching study, Nora Taylor, via a different scenario-that of performance art-reminds us to maintain critical distance. Taylor (2009) is cautious about histories that reduce performance to an offshoot of contemporary art, or that approximate performance and marginality.

Lenzi's background in law glimmers through her careful analysis, concurring with Aronson (1999) that homosexuality has been less well tolerated in Vietnam than elsewhere in Southeast Asia. Aronson (1999: 204) studies legal codes from ancient to contemporary, observing that the absence of laws against homosexuality in Vietnam reified its invisibility in the public realm and served "to deny the possibility of its existence". $\mathrm{He}$ sweeps through other historical sources to track down accounts from travellers and missionaries of the past, dating from the 1600 s, that generally suggest that throughout the ages, unlike its neighbours, the land now known as Vietnam condemned homosexuality. Things are not too different in the twenty-first century. Until the year 2000 it was illegal for gay couples to live together, and homosexuality is still frowned upon, in part because it was only removed from the official mental illness list in 2001 (Mann, 2014). Newton (2012), in her ethnography of female homosexuality in Vietnam, examines its growing community lexicon and three-part lesbian gender system. Navigating the rapid changes in this complex scene, she points out the mechanisms that render it a community that "does not exist" in the eyes of society at large (Newton, 2012: 61). For Newton (2012) and Rydstrøm (2006) sexual activity has been considered a "social evil" (tê nạn xã hội) even in Vietnam's recent history, placing a stigma most heavily on women (Schuler et al., 2006).

In summary, the literature suggests that legal and social constructs had historically obscured homosexuality in Vietnam, to a degree that caused it to be thought of as non-existent or a foreign behaviour that did not occur among Vietnamese people. Photographer Maika Elan (WPP, 2013) and writer Bui Anh Tam (Tran Dinh Thanh Lam, 2004) provide eloquent accounts of how negative media portrayals of gay people prompted them to investigate the topic and develop creative works to combat illinformed stereotypes. Their work and recent changes in legislation are helping to diminish homophobia. Same-sex marriage is not contemplated by law, but the ban on celebrating same-sex wedding ceremonies has been lifted, and as from 2017 the civil code will permit the gender reassignment of transgender people (Anh Vu and Khanh An, 2015).

In parallel to this changing social order, the art panorama manifested tensions of its own, which will be summarized below. Beginning with the premise that homosexuality "exists" in Vietnam, seeing that it now has a mention in the country's legal history, this article places the conflicting subjectivities surrounding cultural norms, the legal framework, artistic innovation and media biases in relation to art production. Focusing on representations of identity "around the practices and pleasures that in the 20th century became known as 'homosexual'" (Ofield, 2005), this discussion takes a contained approach that knowingly leaves out some well-known gay artists yet includes the work of straight-identified ones. To unravel a schematic chronology of nation-specific queer art, the examples find common ground, as in Reed's book, in their capacity to place homosexuality in the foreground.

\section{Art as resistance}

The existence of civil society in Vietnam is questionable (Lenzi, 2015), but activism can manifest in many forms, and art has opened doors for challenging social norms. Pham Vinh $\mathrm{Cu}$ (cited in Nguyen Quan, 2015) believes that from the onset of the twentieth century, the arts in Vietnam became much more relevant than ever they had been in the country's past. For him, Vietnam's literary production of the first half of the century is a milestone in national culture, yet he considers the visual arts to be the significant players during the second half of the century.

Vietnamese writers working in the 1930s, intrigued by characters in French literature who made choices regarding their own fate, unhindered by familial expectations, began a debate about individualism (Phinney, 2008). The discourse of the Tho Moi poets and Tu Luc Van Doan (Self-Reliance Literature Group) challenged some traditional values and paved the way for new forms of self-expression in creative writing. Tran (2012: 376-379) recounts that French author Andre Gide's homosexuality "was an open secret in Vietnam at the time", the 1930s, and explains some oblique ways in which that fact appears in literature by Vietnamese writers and "led to the articulation of individual desire that destabilized the established social order".

Tumultuous socioeconomic problems continued after the Vietnam-American war, and were even exacerbated by the "open door" policy (đồi mó i) begun in Vietnam in 1986 (Drummond, 2006).

The impact of the infrastructural changes was felt principally from the beginning of the 1990s. New provocations shook the visual arts in this period, when Vietnamese artists, although frequently with minimal awareness of contemporary art outside the country (due to Vietnam's closure from after the war to 1986), began to question the production of state-sanctioned art and its emphasis on socialist realism. Where possible, artists shared hard-to-get information on art practices outside Vietnam's borders. Artist Do Hoang Tuong (b. 1960) recalls seeing French art catalogues that his colleague Nguyen Trung (b. 1940) had brought back from his long-desired visit to Paris in 1990. "All we knew were the books of Soviet art from the mid-twentieth century", Do exclaimed (cited in Taylor, 2014: 35). Artist Hoang Duong Cam (b. 1974) explains how as a teenager he copied by hand texts from books that were banned from circulation that he had secretly borrowed from family friends. In this underground manner he and other artists learned about Dadaism, Picasso and other avant-garde artists and movements excluded from the official art discourse (personal communication, 2014).

Throughout the 1990s, along with an influx of foreign art buyers, new art galleries opened in Vietnam. With multicultural 
exchanges from foreign practitioners coming into Vietnam and some Vietnamese artists given the rare opportunity to visit other countries, came the discovery, even if limited, of new art forms beyond the picture plane and traditional media. Artist Thanh Chuong enthused about the choices he now had: "[in] the past, if someone asked a painter to paint a picture, they told the artist what to paint. (...) I can now do what I like and use my own ideas. It is a good time for Vietnamese artists" (cited in Findlay and Hagemans, 1997).

1992 was a good example of the vitality that surged in the Vietnamese artworld. According to art critic Ca Le Thang, 200 artists created 5,500 works that were shown across 25 venues and seen by 400,000 visitors (Findlay and Hagemans, 1997). It was also the year in which abstract art was permitted to hang in public exhibitions, following a relaxation of state regulations, ${ }^{2}$ although government censorship would keep on restricting many forms of self-expression, and continues to be exercised, along with cautious self-censorship. Lenzi (2002) considers that the authorities in post-Doi Moi Vietnam were quite tolerant of the visual arts, as

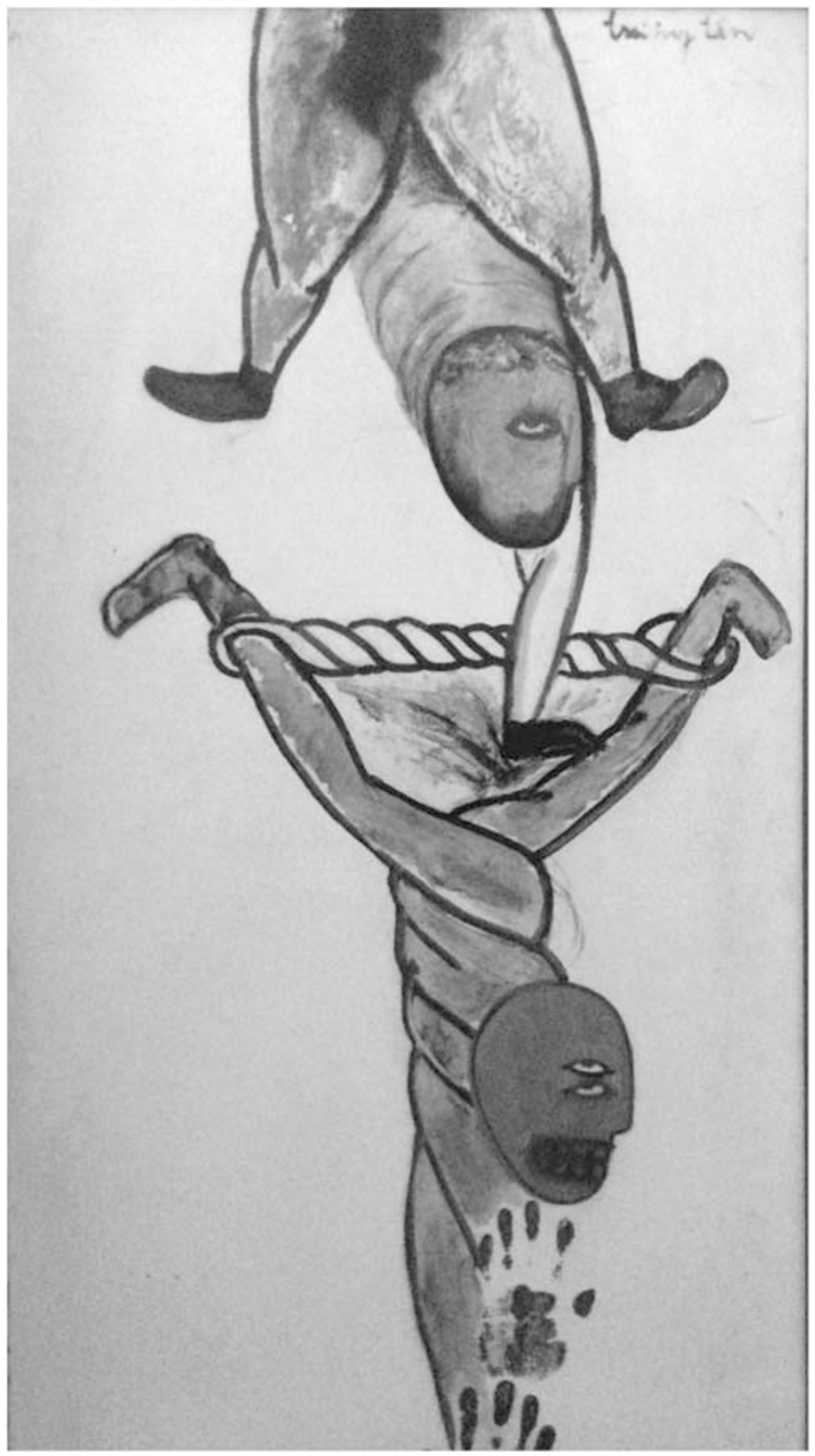

Figure 1 | Circus by Truong Tan (1992). Source: Photograph taken by Truong Tan and reproduced with permission. This figure is covered by the CC BY-NC 4.0 license. does Boitran Huynh (2005), who attributes a mild softening of the Vietnamese government's vigilance of literature and art to the influence of Soviet perestroika. ${ }^{3}$ Chiu and Genocchio (1996: 86) maintain that visual artists were less censored than writers, but document the severity of the problem and believe that "Official censorship of artworks in Vietnam appears to be a relatively recent and sporadic phenomenon". Huynh believes, however, that writers were more vocal than visual artists in calling for reforms, perhaps because the market for Vietnamese paintings was taking off and the resulting commercial potential was a disincentive for painters to change their successful formulas.

The arrival of an art boom in conjunction with newfound creative freedoms sparked a heated debate about the nation's cultural heritage and artistic traditions. In the opinion of Nguyen Quan (2015), when the art market took off in other Asian countries such as Thailand, Indonesia or China, each country had already a defined artistic identity, whereas in Vietnam no national iconography had yet solidified. There had been "an awkward artistic unification in the year after 1975” (Scott, 2015: 205), but historical north-south differences did not vanish instantly. The artworld at this time was not by any means a unified body on an ambitious mission to change the paradigm, as Kraevskaia (2002) has synthesized.

Unsurprisingly, non-conventional images and the fresh potential of installation and performance art were received with mixed feelings, including denial that such pieces could be considered art (Taylor, 2007). ${ }^{4}$ However, forms like installation or performance permitted an innovative form of dissent: "a breach of aesthetic rules" (Radulovic, 2009: 192). Not short of contradictory opinions, the local artworld questioned the artistic worth (as opposed to "commercial value") of paintings of, for example, idyllic rural landscapes that were selling profitably (Talawas, 2002; Nguyen Quan, 2015). For Bui Nhu Huong (2009: 85) beautiful paintings of the nation, or "nice art", derive from an artistic history and a tradition that few people grasp in full. In the face of rapid changes, some perceived Vietnam's past with a romanticizing glow. Taylor's (2007) interpretation of this profusion of countryside scenes, dismissed by some as facile and commercial, is that these works operate, for the most part, as allusions to Vietnam's pre-communist and pre-colonial past; in other words, they are subversive. With such diverse methods of contesting established canons and traditions, one can understand that this animated creative milieu made way for novel artworks, and might be a conducive environment for homosexuals to feel less pressured to remain in the closet.

\section{Queer art in 1990s Vietnam: Truong Tan opens the closet}

From this period, one of the first artists able to leave Vietnam to exhibit abroad was Truong Tan (b. 1963). Tan, who graduated in 1989 , is the most widely known Vietnamese artist who is openly gay. His work, which encompasses painting, sculpture, performance art and installations, is a potent declaration for freedom of expression. Since the early 1990s, his work explores social attitudes by giving visibility to his sexual orientation (Kraevskaia, 2009).

In 1992, preparing for a group exhibition in the School of Fine Arts of Hanoi, where Tan worked as a lecturer, he created a painting called Circus (Fig. 1). This elongated work shows two contorted, upside down figures, apparently male. The top one is pushing one arm towards the space between the legs of the other twisted character, whose ankles are tied up with a white rope or sheet. The rope is a recurrent image in Tan's paintings, symbolizing the restrictions of Vietnam's conservative sociopolitical environment (Tsai, 2014). Tan considers this piece his first queer painting. "My goal was decided", he says, explaining that he was ready to make evident his homosexuality by showing this work and to seriously develop his career as a professional artist. He continued to draw homoerotic imagery, but he kept it 
private for a time (personal communication, 2016). He tested the waters at his first solo show, in 1994, at the Ecole de Hanoi gallery. "In this exhibition, [representations of] men appeared all over the place", he says (personal communication, 2016). Later that year, Tan did an exhibition in Ho Chi Minh City (HCMC) that showed images of erect penises. The artist thinks this imagery is what drove the authorities to start closely monitoring his work, a surveillance that resulted in disquieting censorship the following year (personal communication, 2016). Eighteen of Tan's artworks were taken down from the Cultural Collision exhibition in Red River (Fleuve Rouge) gallery, Hanoi (Chiu and Genocchio, 1996; Huynh, 2005). Promadhattavedi (1996: 36) has observed that Tan's homoerotic artwork is better received in the West than in a society like Vietnam that frowns on individualism, although in "any country Truong Tan's work would be daring".

By 1995, the international media was already describing Tan as "Vietnam's only openly gay painter" (Duffy, 1995: 50). Ofield (2005: 361) finds that " 'coming-out' narratives of homosexual/gay history are often organized around key moments of transition". Tan's artistic "coming out" can be said to have happened in a more physical manner in 1994, in the form of a spontaneous act in his home. To prepare for an exhibition, the artist had asked a few of his students to help. They assisted in wrapping him up in a white sheet, and tied it around him with rope. From 1994 Tan put ropes and chains around his two-dimensional pieces, although he had started collaging objects such as hair and mirrors to his paintings some years earlier (Truong Tan, 2010). Tan had instructed his small team to take photos of him as this living mummy, images that the artist intended to collage onto some paintings (personal communication, 2016). Tan then removed the binding rope and cloth and emerged, symbolically, as a free person (Taylor, 2009; Bui Nhu Huong and Pham Thuong, 2012), and also, some say, as the precursor of Vietnamese contemporary $\operatorname{art}^{5}$ (Bui Nhu Huong, 2010). While this event cannot be considered a formal artistic performance, performance in Vietnam has its origins around the mid-1990s, with Tan himself citing the year 1996 as the starting point (Truong Tan, 2010).

\section{The rise of performance art in Vietnam}

An artistic performance in 1995 by Amanda Heng, an artist invited from Singapore to Hanoi (Radulovic, 2009), was followed, from 1996, by performances by artists Nguyen Van Cuong, Dao Anh Khanh and a collaboration between Tran Anh Quan and Nguyen Van Tien (a.k.a. Tien Van Mieu). ${ }^{6}$ Tan embraced the new medium because, like him, it was alienated from social norms, free from rules and canons (Huynh, 2005: 356). Though all public displays were subject to official regulations, performance art had built no local history from which to construct evaluation criteria or judgments. Until the end of the decade, performances would be uncommon events, of an almost clandestine nature, that offered an alternative to situating art within a gallery setting, which was more at risk of being prohibited by the Department of Information and Culture (Taylor, 2007). Huynh sees a different challenge, and a reason why performances do not attract much audience. She finds that in traditional Vietnamese culture "performance art goes against a strong reluctance to publicly display the 'self' and the taboo of revealing the body" (Huynh, 2005: 358). Vietnamese performances developed quickly, if chaotically, and had a profound impact on how art was perceived (Radulovic, 2009). By the late 1990s, a number of Vietnamese artists had been invited to perform abroad, leading some young Vietnamese artists to erroneously conclude that performance art was contemporary art and vice-versa (Radulovic, 2009). The subtleties of both the development and the place of performance art in Vietnam are elaborated by Taylor (2009), who discerns the differences in styles among the most relevant practitioners. Curator Apinan Poshyananda celebrates performance for its revitalizing capacity of providing "novel perspectives on social and cultural issues" (cited in Lalwani, 2014: 108). By the year 2000, Poshyananda (2000) had seen a change across Southeast Asia's artwork, through the contributions of Asian artists to a critical debate on postmodernism, new media and issues relating to homosexuality.

In 1996, Truong Tan, in collaboration with his student Nguyen Van Cuong (b. 1972), executed what is considered one of the best performances of this early period (Bui Nhu Huong and Pham Thuong, 2012). Mother and Child, or Mother and Son, also known as The Past and the Future according to Bui Nhu Huong and Pham Thuong (2012: 16), was performed at the closing event of an exhibition by Nguyen Minh Thanh at the government sponsored gallery on 29 Hang Bai, Hanoi (Edwards, 1997). In this 10-minute event, Tan curled up on the floor, smeared with red paint to look bloodied and rolled around tormented by Cuong's broom, which swept Tan around. In Bui Nhu Huong's (2010: 80) description of this piece, Tan represents a "violent and warhungry red animal", whereas in another text Tan is metaphorically a piece of rubbish, swept away by the man in a traditional conical hat whose job is to clean up the past and sweep away old dirt to prepare the way for something new (Bui Nhu Huong and Pham Thuong, 2012). The confusion surrounding the title, ${ }^{7}$ and the ambivalent reading of the actions performed say a lot about the enigmatic power of the piece. Political criticism in the work is a plausible deduction, but the gender change of Nguyen Van Cuong, who performs as mother, suggests a deeper queer intention, symbolizing a scene where a homosexual son is brushed aside and hidden away by the family figure that represents the pillar of society. The spilt blood, in this case, pours from the broken family ties, which are also a tie to the community and therefore to the nation. It is significant that the "mother" is wearing a traditional conical hat ${ }^{8}$ of the type widely used in Vietnam, associated with tradition and the rural, which, as we have seen, is a bone of contention in the Vietnamese quandary on the characteristics of the nation's art. This performance, therefore, seems to put on the same scale the country's limited tolerance of homosexuality with the equally poor acceptance of innovations in artistic themes and media. Radulovic (2009) documents the offence and astonishment that this performance caused, noticing how, on the one hand, it fed a mistrust of new trends and their financial (in)viability, and, on the other, it challenged, reformulated and even reclaimed ideals of artistic beauty, which until then had been the domain of the cultural administration.

\section{Queer art in Vietnam in the 2000s: homosexuality in the public realm}

Zhuang Wubin (2010) recounts the forked origins of photography in Vietnam, determining that the first local generation of photographers in post-Doi Moi HCMC are a few practitioners, born around 1950, able to break out of the self-taught "tradition" that had been the norm in the post-1975 era. Findlay and Hagemans (1997) reiterate parts of the narrative on "Vietnam's own fine photographic past", observing that photography exhibitions were becoming more frequent in the 1990s and that photography was the most visible of new artistic developments.

An artist who has produced work that questions social acceptance of homosexuality is photographer Ngo Dinh Truc (b. 1973). "How to whisper secretly in public?" he asks in his artist statement about his series The Same [Gender] (Cùng Gie [Gender] p), from 2007 (Ngo Dinh Truc, 2015). In Vietnamese, the phrase "the same/the same ones" can also mean "the same gender". 
The work is a selection of images with text on. Commercial photos of luxurious interiors suggest an upscale lifestyle: a double bed in a hotel room with a spectacular view, two wineglasses on a table for three, an elegant bathroom with two urinals side by side, an office with two identical desks side by side and so on. Ngo Dinh Truc describes these photographs as "neutral" because they derive from his commercial work as an interior photographer. There are no people in the scenarios, leaving us to guess who uses the double bed, drinks the wine or shares the office. Superimposed catchlines over the photographs translate as "The same [gender]", "The same ones/gender hang out together", "the same ones/gender have coupled up", "The same order and discipline", "The same ones/gender are close" or "The same ones/gender tuck one another in", all of which in Vietnamese have an ambiguous reading due to homonymy and word play. The texts over these photographs in one sense could be interpreted as merely descriptive, but the double meaning is intentional, designed to provoke a reinterpretation of the idea of gender.

This queer art project is not a performance per se, but has a performative element to its public presentation. Truc put colour posters of these artworks on the streets of Hanoi and Saigon, and handed out flyers to passers-by. The intention was to elicit a response from the community and to instigate a discussion on gender and homosexuality. Curator Nguyen Nhu Huy (2009) believes that this could be the first instance where a Vietnamese artist has used art to interact with the public space in such a way, although he considers this intervention to be more akin to activism than to an artistic performance. Nhu Huy's enthusiasm is directed towards the reach of this work, it reaches the general public, not just the gallery-going public. This detail is what prompts the curator to link this work to activism, an activity that, since the Guerrilla Girls at least, can be ascribed to a number of contemporary artworks all over the world.

When Huy talks of how this work affects "the collective mind" (Nhu Huy, 2009: 92), he seems to inflate how much this transient, public imagery might impact the locus of society's moral consensus, the place where ideologies that condemn homosexuality are rooted. There are abundant ethnographic studies on public space in Vietnam ${ }^{9}$ that, following Taylor's (2007) work, could be worth analysing in relation to Huy's intuition. On the other hand, Huy's call for impact measurement reminds us of corporate practices in marketing. Truc's aesthetics borrow from advertising. The photographs of perfect settings marked by a slogan, once in the public realm, are interpreted within known parameters. The audience is not destabilized by the medium, which is recognized as part of the urban marketing clutter. The familiar form of the street poster helps to make the message more seductive. It can easily be overlooked, but it creates curiosity without seeming too intrusive or unintelligible, something that many other outdoor artworks-or performances-might do. The effectiveness of the artwork, like that of a promotional campaign, Huy posits, must be measured by its capacity to effect change, even if subtle, in the viewer. Alas, no data collection was planned into the art intervention, but Ngo Dinh Truc has created a valuable exploration of the photograph as a vehicle that shifts from commercial to artistic purposes.

\section{Out and proud but hidden}

Himiko Nguyen (Nguyen Kim Hoang, b. 1976) is not an artist that one would call a photographer because of the multidisciplinary nature of her work, yet her photographic practice is central to the artworks discussed next. Her photographs of female bodies are worlds apart from the clichéd female beauties in Vietnam that Abby Robinson (2006) has become fatigued with, easy pictures where that "which is important is immediately evident".
Himiko's photographs of women from her series Closer (2007), and Come Out (2011) and Come Out II (2014) are highly innovative. By her own admission, she has tried to push the boundaries by choosing the nude as a theme in a country where naked images are not permitted (personal communication, 2015). Aiming to reassure the general public that nudes are not equal to pornography, these projects achieve two main things. On the one hand, as she declares, these works chip away at some of the prejudices that a national education insistent on condemning "social evils" has built up. On the other hand, they circuitously present images of female desire, where there is no "sexual object" because both photographer and subject have agency.

Whereas Truong Tan's strategy of painting overtly sexual, erotized nudes was his way of rejecting a dominant aesthetic that stood as apolitical (Chiu and Genocchio, 1996: 89), Himiko obscures eroticism by dramatically cropping or hiding the nudes, creating images that are the opposite of blatant. This could be interpreted as an emphasis on sensuality, or a method for circumventing censorship, yet the strategy empowers the gaze by authorizing it to examine attentively, to not lazily rely on immediate, obvious impressions. In addition, it reflects the situation of being in the closet, of hiding one's private life.

The warm-tinted photographs from Closer depart from the genre of portraiture and hint to the abstract, both by virtue of a limited colour range and because they capture close ups or unconventional angles and poses. The title, while describing the eye/camera lens' proximity to the glowing body, is a reminder of the potential of art to draw people together in conversation. In talking about her creative process, Himiko says that "normal concepts of the body are extinguished, when one gets closer it is like language with no limit, no distinction" (Nguyen Himiko, $2007,2013)$. A queer reading of that sentence finds a discrete call for social divisions to break down, helped by the common language that can arise spontaneously from close interactions. Distinct from Truc's public distribution of messages, Himiko's works seem to politely request that the public be more open to think about homosexuality without judgment, merely observing and accepting, as in meditation, a practice she engages in.

Himiko laments the unwritten rules and constraints that she notices in Vietnamese society. Her work, she says, is "about gender, about the third sex in a very strict (...) society" (personal communication, 2015). This "third sex" may be a reference to transgender or queer fluidity, or to the three lesbian identities discussed by Newton (2012). The constraints Himiko talks about are evident to Newton, who has found lesbophobia to be a tool used by the state to exert control, though she has seen an appropriation of it on the part of the lesbian community to turn it upside down.

Come Out (Fig. 2) is an autobiographical project. Self-portraits of the naked artist, often in a yoga pose, softly lit against a dark background, are encased in black boxes mounted on the wall like cupboards. Each box has a hole in the centre for the viewer to look in. Upon pressing a light switch, the photograph inside becomes visible. The visibility that the title itself calls for is thus interactive. The coming out process requires the help of a viewer who will switch on the light. Most importantly, the boxed framing device has the commanding job of channelling the viewer's gaze to completely reverse the conventional power structure gaze/nude.

The newer version, Come Out II, is larger in scale, a beehive of black boxes, stacked and lined up occupying a whole room. The inference of such a large work is that the action required to elicit a coming out is now more social than individual. It takes a collective to work together and bring light to a hidden issue. The creation of these two versions, a few years apart, is hopefully a welcome sign of the speed of changes in the public discourse on Lesbian Gay Bisexual Transgender (LGBT) issues. 


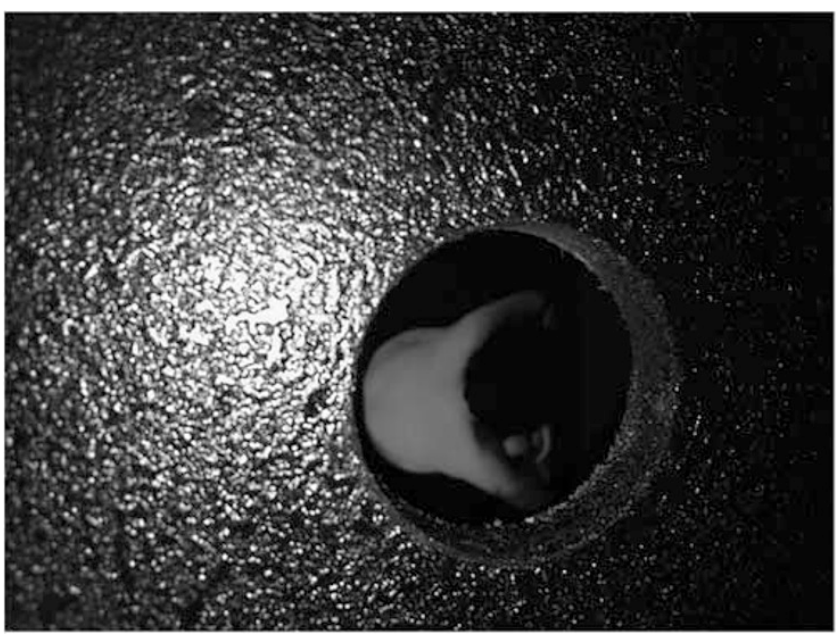

Figure 2 | The peephole in the wooden box over one of Himiko's photographs from the Come Out series. Source: Photograph taken by Cristina Nualart (2011) and reproduced by permission of Nguyen Kim Hoang. This figure is covered by the CC BY-NC 4.0 license.

\section{Documenting the queer decade}

Art, in many societies, is not a medium that reaches the masses. This is the case in Vietnam, where the events and artworks mentioned, although harbingers, have had a small impact on a nation-wide scale outside artistic circles. A documentary project, Pink Choice (2012), has been more successful in widely spreading an anti-homophobic message. It comes from a sociologist turned documentary photographer, Maika Elan (Nguyen Thanh Hai, b. 1986). Pink Choice has had much media exposure following its exhibition in Hanoi (2012) and due to it winning the 2013 World Press Photo prize and other awards.

In 2011, Maika Elan realized that if she were gay, she would not dare to come out because Vietnamese media portrayed homosexuality as "a tragic fate" with multiple negative connotations (WWP, 2013). The black boxes in Himiko's artistic critique are a metaphor of this media bias, we realize. On her part, Maika also encountered people who professed to be open-minded, but reacted with disgust at expressions of same-sex affection. In her circle of acquaintances, however, she saw a different story: people would come out quite early to supportive families and lead happy lives. She embarked on a research mission. Her procedure to contest media negativity and to foster acceptance was to reclaim beauty: "when something is beautiful people just accept it as it is", she says (WWP, 2013). Free from antagonistic ideas of beauty that artists in Vietnam had debated during the 1990s, the press release states: "Love is beautiful" (AAA [Asia Art Archive], 2012), with a simplicity useful for widespread dissemination.

Irrespective of beauty constructs, the images are powerful expressions of affection, support and complicity between individuals whose identity is a key part of the work. Unlike other projects discussed above, Pink Choice does not have a performative element in its final form, although the people it portrays were able to choose to "perform" their self-representation, or remain candid. Maika, and the people she photographed, decided to move away from anonymity and discretion, to combat the lack of identity that media cloaks gay people in. The photographs collect routine moments in the lives of gay and lesbian couples, inserting them into parameters of the "normal".

The decision of participants to pose for these photographs cannot be underestimated. Artist and critic Viet Le (2015), on his part working on an ethnographic photography project on gay male nudes, found his own coming out, in the relative safety of the United States, difficult. Discrimination has no borders, but it is not preventing people from taking risks. Queer lifestyles seem to be a popular theme for creations that, as Maika hopes, will help to demystify and make "real" the lives of gay people (WPP, 2013).

Twenty years after Truong Tan painted his first homosexual artwork, Nguyen Quoc Thanh (b. 1970) created a photographic series that explores the formation of male homosexuality in Vietnam, A Soldier's Garden (2012). Whereas Tan, and to some extent Himiko, started their explorations around their personal experiences, Thanh omits references to himself, and, like Maika Elan, embarks on a research of the gestation of feelings and desires in others. Thanh's aim with A Soldier's Garden is to explore homosexual desire within a group of young men living in close proximity.

Set in a location that affords some distance from peers who may see or hear, trainee soldiers are captured in a familiar portraiture style, at night, in the gardens of their military residence. The process, Thanh found as he worked, manifests the power of state conditioning. The young men he points his camera at hover on the uncertain space between being at ease for a casual, friendly photo, and being watched by officers whose vigilance sanctions official behaviour codes. This awkward position translates onto the photographs as "distances-between the subjects, between the image and the viewer, between darkness and light" (Thanh cited in Zhuang Wubin, 2015).

The images are, like Himiko's, not very explicit, and bring to the fore elements of the private sphere. Thanh works in an official, restricted-access space, which he has had to request permission to use. In this case, the bureaucratic procedure of getting a licence to enter the barracks is undergone even before the works are made. A licence will be required again later, to exhibit the works. Closer or Pink Choice celebrate the freedom of privacy, whereas the Soldier's Garden reverberates with stagnant official impositions. Decades prior, grinding restrictions spurred Truong Tan to leave his institutional job as a lecturer (Lenzi, 2002; Naziree and Phan, 2006). In 1997 he moved to Paris, where he discovered feelings of freedom beyond his expectations (Tsai, 2014).

\section{The ripples}

The artworks above have laid down the groundwork for a more inclusive future. Truong Tan's visual narratives of homosexual love shook the Vietnamese artworld, yet they inspired many to move away from convention. Artist and curator Tran Luong-himself a creator of powerful performances-was inspired by Truong Tan's bravery. Over a decade later, Luong made a rather melodramatic statement against the continued marginalization of gay people:

... the voice of homosexual class has been refused point blank for 14 years since Truong Tan exhibition in 1995. We should never ignore the fact that homosexuals account for at least $2 \%$ of the total population of 80 millions. They have lived in the dark for two thousand years without happiness [sic]. (Tran Luong, 2009: 184)

This well-intention comment from an open-minded artist is indicative of how pervasive ideologies are on the exceptionalism of queer identity, and their emotional well-being. Tran Luong's statistic (2\% of the population is gay) is not backed up by any source, but may be an intuitive, if questionable, interpretation of the Vietnam population census, which in 1989 noted that the percentage of men who never marry is between $0.9 \%$ and $3.6 \%$, depending on the region (Aronson, 1999: 208). ${ }^{10}$ Of course there can be no direct correlation between marriage and sexual orientation, but Aronson uses the census data to explain how Vietnamese tradition of filial obligation made it unnecessary for civil authorities 
to create laws against homosexuality. The weight of tradition by itself would lead to people getting married (Aronson, 1999: 208). As we have seen, two generations of artists are working to reduce the friction of old traditions on a vibrant, young Vietnam, although many artists avoid confrontation and play it safe (Kraevskaia, 2002).

Another challenge associated with homosexuality has been AIDS. The AIDS crisis in the United States united sufferers and supporters through the ACT UP network, organizing performances called "die-ins" (Foster, 2003), that, as the name implies, recall Truong Tan's role in Mother and Child. Although from the mid-1990s USAID (2015) started an HIV/AIDS programme in Vietnam, the AIDS crisis in Asia was less visible, or visible in a troubling way. Imagery on Vietnamese anti-AIDS posters suggests that the disease is "associated with drug use and prostitution" (Chiu and Genocchio, 1996: 89). ${ }^{11}$ Truong Tan responded with some AIDS-related paintings that show wasted male bodies. ${ }^{12}$ A number of authors compare Tan's drawings with those of Keith Haring (Lenzi, 2002, 2015; Chiu and Genocchio, 2010; Bui Nhu Huong and Pham Thuong, 2012). Artist Hoang Duong Cam seems to recall that the comparison between Truong Tan and Keith Haring was first made by Bradford Edwards (personal communication, 2014). Tan himself acknowledged Haring's influence on his drawing style during his formative period (Chiu and Genocchio, 1996: 89), but, although both artists create thick-lined drawings with a spontaneous quality, Tan's are rendered with more natural proportions and lack the cartoonish rhythm of Haring's graffiti. The recurrence of the comparison is legitimate but risks entrenching rigid associations to gay and AIDS activism and to group homosexual artists together.

As more visibility is given to queer identified people, the less likely it is that they will all be bundled together. Many of the artworks discussed above predate the following events, which have a broader, more popular, reach: Vietnam's first Gay Pride parade was celebrated in 2012 (AP, 2012), the same year that My Best Gay Friends sitcom debuted on YouTube to become an instant hit (DeHart, 2013). In 2013, Nguyen Quoc Thanh, a founding member of the Hanoi art space Nha San Collective and author of A Soldier's Garden, initiated Queer Forever, a queer art festival in Hanoi that encompasses art exhibitions, conferences and concerts. The festival is growing year on year, and is widely publicized via independent online publications. ${ }^{13}$ Offord (2013: 339) notices patterns in LGBT activism that signal a divergence between Southeast Asian and Western societies, but if one may extrapolate the findings made by Calzo and Ward (2009) on the presence of gay and lesbian characters in the US media, Vietnam's increasing visibility of homosexuals may also lead towards wider social acceptance (see Phillips, 2013 for a recent survey of the situation). A Vietnamese news article gives an inspiring example that indicates that media exposure can help to normalize homosexuality (Tran Dinh Thanh Lam, 2004).

Censorship has been mentioned in this discussion regularly, and almost as rhythmically has affected Tan and Himiko over their careers (NCAC, 2007; Naziree, 2010). Ngo Dinh Truc's urban intervention could avoid permit requests, because only conventional exhibitions in a venue open to the public need the licence from the Ministry of Information and Culture.

A look at the National Coalition Against Censorship (NCAC, 2007) listing of Himiko's "Closer" gives an indication of the issues the censoring board takes into account before granting, or not, a licence to exhibit. The irony is that it is not just the Vietnamese government censoring her nude photography, it is also Facebook (see ). The social network, in turn not officially approved, is used on an unprecedented scale in Vietnam, which has one of the highest Internet censorship circumvention rates in the world (Sharbaugh, 2014).
The Deputy Head of the Culture and Art Department says there is no list of forbidden topics, but "artists are advised not to show work that opposes the party and the government, or goes against traditional customs", such as modest attire (Brown, 2012). A gallerist of Vietnamese art known to this author has had more trouble securing licences to show artworks with frontal nudity than with any other topic (personal communication, 2016). The prestigious art centre in HCMC, San Art, recently closed its Laboratory building devoted to artist residencies, due to continued censorship issues. Nearby, San Art's main gallery space had taken to exhibiting the official letters that denied the necessary exhibition licence in lieu of banned artworks. This happened with staged photographs by Phan Quang and images of Cambodian bomb ponds by Vandy Rattana. ${ }^{14}$ None of the photographs by either artist had any direct, queer theme, although it should be said that the gallery has not, to my knowledge, shown any overtly queer artworks. My personal impression is that Vietnamese censors do not show a distinct bias against homosexuality, as authorities systematically reject any work that has political or sexual overtones.

\section{Conclusion}

This article has looked for connections between Vietnam's structural development in the latter part of the twentieth century, its modern and contemporary art history, and, within that, a number of queer art projects created since the 1990s.

In post-Doi Moi Vietnam, at the same time as state policies took effect, the first generation of contemporary art performers and photographers added to the innovative ripples that were shaking art thinking and practice. The decade of the 1990s is considered to mark the beginning of Vietnamese contemporary art, and it is interesting to find that art with homosexual content appears at the same time. Although not all queer artworks have been explored (a task too lengthy to be accommodated here), the timeline suggests that, since the breakthrough that Truong Tan made in the early 1990s, queer artworks have been created with increasing frequency, and are also being created by straight people, which is an important sign that it is not just the queer minority who are interested in this.

Selecting topics such as explicit male nudes and same-sex arousal, low awareness about AIDS or government abuse-in the form of surveillance, restrictions or corruption-Truong Tan caused so much shock that he conceivably made it easy for other artists to take risks. Unfortunately, the censorship he experienced was also much talked about, and possibly hindered other artists from developing unconventional work. Nonetheless, important artists of his generation and later, including Tran Luong and Hoang Duong Cam, have expressed their indebtedness to his work.

Tan's overt homosexuality has arguably contributed significantly to his success as an artist, although the repetitive expectations placed on him by the outside world have been a burden. He denies that homosexuality is the only topic he is interested in. " $[\mathrm{M}] \mathrm{y}$ works are about humanity in general. My private life is private", he exclaims in a critique of the categorization of a person by their sexual orientation (cited in Tsai, 2014). In recent years, his installation pieces, for example Hidden Beauty (2007) or Mother of Peace (2009), show a strong critique of the Vietnamese government that is not related to sexual issues.

Performative works of queer art in Vietnam have occupied an important part of the discussion. It has been stated that the development of performance is not directly contestative, but arguments explain that inherent characteristics of performance art (such as its "portability", spontaneity, freedom from canons or its ability to stun audiences, as in the reactions to Mother and Child described by Radulovic) were conducive to using it as an art 
practice of resistance. Nevertheless, there is no evidence to suggest that it was mostly used to manifest queer discontent. If anything, it appears to have been used in equal parts to challenge academic art and to critique political issues. Fundamentally, performance was the newcomer on the Vietnamese art playground and experienced some bullying. The rejection was not so monolithic as to concern us that the alienation of the art form will drag on indefinitely. As Taylor (2009: 173) says, "in many ways [performance art] entered the mainstream".

Two-dimensional works are a more accepted, established medium, one that is still perfectly valid for creating affront. Truong Tan's drawing style breaks with tradition in its simplified, linear aspect, but pays homage to tradition with its material constitution: Tan uses rice paper and lacquer dear to Vietnamese tradition. His principal achievement is in the discomforting choice of subject matter, sometimes described as pornographicsomething that in other countries would be dismissed as selfinflating shock tactics. In Vietnam it was an example of an individual rejecting national power structures and it activated both contemporary art and homosexual visibility.

A salient point is the wilfulness with which some artists work against the grain. Nguyen Quoc Thanh's public activism (Queer Forever festival) gives credence to the impression that Vietnam's homosexual community can come out of hiding in relative safety, with the cautions that transpire from Newton's (2012) research. Artists Tan and Himiko clearly articulate their objective to defy censorship and to express themselves freely. Those objectives are not tied in unison. Since censorship can be unpredictable, it is not in direct opposition to self-expression. Himiko's comments make it clear that her actions are not to be perceived as an angry rebellion to authority. On the contrary, they indicate a thoughtful understanding on how national ideology is implemented and how it is naturalized by the general population. In Closer we find a good example of intellectual retaliation. She combats pervasive stereotypes with "homoeopathic" methods: by zooming in on the allergen and dosing it. Ngo Dinh Truc and Maika Elan did not ideate The Same [Gender] or Pink Choice with the same personal drive for selfexpression that we sense in Tan and Himiko, but those equally laudable projects demonstrate clever reflections on how to avoid instant public dismissal. Like the best pedagogy, they offer a new layer of learning that mines ingrained knowledge and slowly erodes by incompatibility. All three projects use their visual power to activate emotions. The linguistic ploy in The Same [Gender] is an effective method for making distinct the invisible assumptions encoded in the culture. The hidden images in Come Out, in their interactive framing device, generate a similar situation, tending to the phenomenological rather than the verbal, however.

Pink Choice and Closer lay claim, clearly articulated by their creators, to a vindication of beauty. Even if no definitions of beauty were specified or proposed, it is not because both photographers assume that beauty ideals are universal, but because the concept of beauty is so linked to Vietnamese identity (the beauty of the nation, in its widest sense, is historically entrenched) that it has an unmistakeable resonance. As Maika explained, beauty is a tool that makes her work acceptable to those who would reject it for its homosexual content. An excellent account of the pervasive ideology of beauty, to a degree that it can be used as a social control mechanism, comes from Erik Harms (2012), whose analysis centres on ideals of urban beauty. It is worth recalling here the artistic debates of the 1990s, in which innovations such as performance art were denounced by many as "ugly". Himiko and Maika's photographs do not violate standard expectations about art to the extent that performance did decades earlier, thus they share some affinity with traditional art, which in its most basic construct is perceived as beautiful "by default".

As for the international picture, the development of queer art in Vietnam and in the United States highlights a curious difference in the status of the artists. For the American artists in the mid-twentieth century-Reed (2011) cites Paul Cadmus and Jared French-queer themes were possible only if they gave up pretensions of becoming avant-garde figureheads. The American establishment could tolerate some skilful images of male nudes in the light of Renaissance tradition, but would never sanction other types of explicitly homoerotic depictions (although these were known to circulate in trusted circles of like-minded art lovers and collectors). As someone informed a young, eccentriclooking Andy Warhol a few years later, "the major painters try to look straight" (cited in Reed, 2011: 171). This contrasts with the Vietnamese scenario, almost in polar opposition. Vietnamese artists, at least Truong Tan (since he is of the generation active in the 1990s, when avant-garde art-arguably-begins in Vietnam), appear to enter the avant-garde rather than exit it when they take on queer subject matter. In the past, some Vietnamese artists believed that engaging in performance art made them contemporary artists. If LGBT themes are seen as the key to "current" contemporary art, perhaps gay art will merely be the next trend. During the 1990s, many critics in Vietnam's effervescent artworld felt that performance art was a trend for lazy artists (for example, Miscault, 2015). Time has shown that the experimentation that took place in Vietnam may not have resulted in a string of masterpieces, but overall, the art form has contributed some singular works to the world.

Through examination of post-Doi Moi cultural production, this study has tried to document how homosexuality has shifted its way into the margins of visibility, even if it is still far from mainstream. While this study does not purport to be exhaustive, in the period from 1992 to 2015, the creation of queer artworks has been growing in quantity and in type of media. The findings show that queer artworks are generated from one of two places: a drive to resist established behaviour codes, or a need to find answers, to explore and research some aspect of homosexuality. It is up to debate if the Vietnamese social imaginary is changing its awareness, understanding and levels of tolerance as a consequence of, or aided by, queer cultural works.

\section{Notes}

1 Reed (2011: 240-242) has articulated the language shifts around terms like gay art and queer art. This article uses the more prevalent term queer art to designate art with themes that address homosexuality in some way, irrespective of whether the works were made by straight or queer identified artists, or if these are publicly out

2 Abstraction was permitted from 1990 according to Huynh (2005: 142), or from 1991 according to Taylor (2012: 10), but the first licence-granting authorization for a specific exhibition to feature abstract art was given in 1992 (Kraevskaia, 2009: 106). 3 Chiu and Genocchio (1996: 85) call Doi Moi "the Vietnamese perestroika".

4 The debate also touched upon the ontology of contemporary art, questioning if Vietnam was even capable of producing such art. The idea mirrors colonial patterns in the Western hemisphere, according to Desai (2005). Until the early 1990s, the president of the Asia Society never witnessed serious curatorial consideration for inclusion of contemporary Asian art into collections in the United States. Desai illuminates his point by citing art critic Holland Cotter: "How could avant-garde art exist anywhere in the 'timeless' cultures of what we monolithically call Asia? If it did, it could not be any good. Too Western, or too Asian. Or too little of one or the other" (cited in Desai, 2005: 104).

5 Radulovic (n.d.) sees Tan as initiating performance art in Vietnam, a statement corroborated by Boi Tran Huynh who gives the year 1994 (Huynh, 2005: 356, 358). The expression "contemporary art" employed by Bui Nhu Huong illustrates the discrepancies that Vietnam was having on the meaning of that term.

6 These two artists date their performance in the grounds of Hanoi's Temple of Literature to 1997 (Tien Van Mieu, n.d.), although Taylor $(2007,2009)$ places it in 1995. This and other minor inconsistencies in the details of artworks point to the 
scarcity of documentation on this generation of artists, possibly because the artists had little sense of the potential future impact of their experimentations.

7 The piece is known in English as Mother and Son in Radulovic (2009: 191) and Lenzi (2015: 16), Mother and Child in Bui Nhu Huong (2010: 12) or The Past and the Future in Bui Nhu Huong and Pham Thuong (2012: 16). The discrepancy in the recorded title is all the more puzzling, as the same author, Bui, contributes to two of the sources.

8 Incidentally, the conical leaf hat is becoming a performance prop all by itself, it would appear from Harms' (2011) findings, whereby street vendors choose to wear traditional garments as part of their improvised "marketing strategy" to sell their homemade goods.

9 For example, Drummond (2000) or Thomas (2001).

10 Interestingly, in 2012 a small-scale gender report in HCMC found that out of 189 respondents, $2 \%$ declared to be neither female nor male (LIN Center for Community Development, 2012)

11 Official posters and billboards of this type continued to be displayed in Vietnam until at least 2015, as witnessed by the author.

12 For example, the works on paper Contagiously Sick, which can be viewed online (Truong Tan, 2010), The Hunter for Aids and Aids Fuckers Go Home, both from 1995, or the 1994 installation titled I Like You I Like HIV discussed in Chiu and Genocchio (1996: 90).

13 The Hanoigrapevine.com is an online information network on art and culture with a long trajectory. It is written mostly in English and run by volunteers. In recent years other online art and culture magazines have sprung up, although some are short lived. Facebook is a very popular method for distributing information in Vietnam, for reasons thoroughly articulated by Sharbaugh (2014).

14 This information is public and online on the San Art Facebook page or their Website. See, for example, http://san-art.org/exhibition/bomb-ponds/.

\section{References}

AAA [Asia Art Archive]. (2012) The Pink Choice. Online publication, 5 June, http://www.aaa.org.hk/WorldEvents/Details/20830.

Anh $\mathrm{Vu}$ and Khanh An (2015) Vietnam recognizes transgender rights in breakthrough vote. Thanh Nien News, online publication, 24 November, http://www.thanhniennews.com/society/vietnam-recognizes-transgender-rightsin-breakthrough-vote-54121.html.

AP (Associated Press). (2012) Demonstrators hold Vietnam's 1st gay pride parade. CBS News, online publication, 4 August, http://www.cbsnews.com/news/ demonstrators-hold-vietnams-1st-gay-pride-parade/.

Aronson Jacob (1999) Homosex in Hanoi? Sex, the public sphere, and public sex In: Leap William (ed) Public Sex/Gay Space. Columbia University Press: New York, pp 203-221.

Bui Nhu Huong (2009) Modern Vietnamese art: Process and identity In: Lee Sarah and Nhu Huy Nguyen (eds) Essays on Modern and Contemporary Vietnamese Art. Singapore: Singapore Art Museum, pp 78-86.

Bui Nhu Huong (2010) Art in Vietnam today In: Connect: Vietnamese Art Scene; (Update: Kunstszene Vietnam). IFA (Institut für Auslandsbeziehungen): Berlin and Stuttgart, Germany, pp 76-85.

Bui Nhu Huong and Pham Thuong (2012) Vietnamese Contemporary Art 19902010. Knowledge Publishing House: Hanoi, Vietnam.

Brown Marianne (2012) Performance art tests social, political taboos in Vietnam. Tribune Business News, online publication, 28 February, ProQuest, http:// 0 -search.proquest.com.cisne.sim.ucm.es/docview/923642258? accountid=14514.

Calzo Jerel P and Ward Ward, L (2009) Media exposure and viewers' attitudes toward homosexuality: Evidence for mainstreaming or resonance? Journal of Broadcasting \& Electronic Media; 53 (2): 280-299.

Chiu Melissa and Genocchio Benjamin (1996) A silencing sexuality. Third Text; 10 (37): 85-90.

Chiu Melissa and Genocchio Benjamin (2010) Contemporary Asian Art. Thames \& Hudson: London.

De Miscault Dominique (2015) Les printemps vietnamien et ses suites. Regards sur l'art vietnamien des années 1990 jusqu'à aujourd'hui In: Herbelin C, Wisniewski B and Dalex F (eds) Arts du Vietnam. Nouvelles Approches. Presses Universitaires de Rennes: Rennes, France, pp 153-157.

DeHart Jonathan (2013) My Best Gay Friends big YouTube Hit for Vietnam. The Diplomat, online publication, 4 April, http://thediplomat.com/2013/04/my-bestgay-friends-big-youtube-hit-for-vietnam/.

Desai Vishakha N (2005) Beyond the "authentic exotic": Collecting contemporary Asian art in the twenty-first century In: Altshuler Bruce (ed) Collecting the New. Princeton University Press: Princeton, NJ, pp 103-114.

Dinh Thanh Lam Tran (2004) Arts weekly/Vietnam: Closet gays slowly coming out. IPS News, online publication, 20 July, http://www.ipsnews.net/2004/07/arts-weekly-vietnam-closet-gays-slowly-coming-out/.

Drummond L (2000) Street scenes: Practices of public and private space in urban Vietnam. Urban Studies; 37 (12): 2389.

Drummond Lisa (2006) Gender in post-Doi Moi Vietnam: Women, desire, and change. Gender, Place and Culture? 13 (3): 247-250.
Duffy Dan (1995) Cultural collage: Vietnam's new breed of artists leaves lasting impressions. Far Eastern Economic Review; 6 (July): 50-51.

Edwards Bradford (1997) A stir in the ranks. Asian Art News 7(2), online publication, http://www.vietnamartist.com/a-stir-in-the-ranks/.

Findlay Ian and Hagemans Helene (1997) Changing times. Asian Art News 7(2), online publication, http://www.vietnamartist.com/changing-time/.

Foster Susan Leigh (2003) Choreographies of protest. Theatre Journal; 55 (3): 395-412.

Harms Erik (2011) Saigon's Edge: On the Margins of Ho Chi Minh City. University of Minnesota Press: Minneapolis, MN.

Harms Erik (2012) Beauty as control in the new Saigon: Eviction, new urban zones, and atomized dissent in a Southeast Asian city. American Ethnologist; 39 (4): 735-750.

Huynh Boi Tran (2005) Vietnamese aesthetics from 1925 onwards, PhD, University of Sydney, online publication, http://ses.library.usyd.edu.au/handle/ 2123/633.

Kraevskaia Natalia (2002) Vietnamese modern art: Change stagnation potential strategy. Vietnamese Fine Art in the 20th Century Conference, Hanoi, online publication, $30 \mathrm{March}$, http://www.vietnamartist.com/vietnamese-modern-artchange-stagnation-potential-strategy/.

Kraevskaia Natalia (2009) Collectivism and individualism in society and art after Doi Moi In: Sarah Lee and Nguyen Nhu Huy (eds) Essays on Modern and Contemporary Vietnamese Art. Singapore: Singapore Art Museum, pp 103-110.

Lalwani Bharti (2014) Arguing for regional perspectives: Two germinal texts capturing the ethos of conceptual art from Southeast Asia. Take on Art IV (15) online publication, http://www.academia.edu/10710840/Art_Criticism_Arguing for_Regional_Perspectives_2014.

Lenzi Iola (2002) Hanoi, Paris, Hanoi, the evolving art of Truong Tan + Nguyen Quang Huy. Art Asia Pacific; 35, 64-69.

Lenzi Iola (2015) Looking out: How queer translates in Southeast Asian contemporary art. Intersections: Gender and Sexuality in Asia and the Pacific, 38, online publication, August, http://intersections.anu.edu.au/issue38/lenzi.html.

LIN Center for Community Development. (2012) Survey on gender perceptions. Online publication, August, http://linvn.org/about-lin/lin-s-impact/reports.

Mann David (2014) Leading the way: Vietnam's push for gay rights. Is one of Asia's most repressive states paving the way for gay marriage? The Diplomat, online publication, 18 April, http://thediplomat.com/2014/04/leading-the-wayvietnams-push-for-gay-rights/.

Naziree Shireen (2010) How to Be and Angel. Thavibu Gallery: Bangkok, Thailand Naziree Shirin and Thuong Phan Cam (2006) Impressions and Expressions: Vietnamese Contemporary Painting. Thavibu Gallery: Bangkok, Thailand.

NCAC. (2007) Closer (Photographic exhibition). Online publication, http://wiki. ncac.org/Closer_(photographic_exhibition).

Newton Natalie N (2012) A queer political economy of community: Gender, space, and the transnational politics of community for Vietnamese lesbians (les) in Saigon. PhD, University of California, Irvine, online publication, http:// pqdtopen.proquest.com/doc/1267776545.html?FMT = ABS\&pubnum $=3547300$.

Ngo Dinh Truc (2015) Photography. Ngo Dinh Truc.com, online publication, http://www.ngodinhtruc.com/en.html.

Nguyen Himiko (2007) CLOSER, Himiko Nguyen Blospot.com, online publication, April, http://himikonguyen.blogspot.com.

Nguyen Himiko (2013) Incidents of censorship in FB. Himiko Café Blogspot.com, online publication, 16 August, http://himikocafe.blogspot.com.es/2013/08/suco-kiem-duyet-o-fb.html.

Nguyen Nhu Huy (2009) Redefining the past and transforming public space: Two new strategies of Vietnam contemporary artists in the early years of new centuries [sic] In: Lee Sarah and Nhu Huy Nguyen (eds) Essays on Modern and Contemporary Vietnamese Art. Singapore: Singapore Art Museum, pp 87-93.

Nguyen Quan (2015) Mouvement et inertie. L'art vietnamien pendant les années 1990 au debut de 2000 In: Herbelin C, Wisniewski B and Dalex F (eds) Arts du Vietnam. Nouvelles approches. Presses Universitaires de Rennes: Rennes, France, pp 145-152.

Offord Baden (2013) Queer activist intersections in Southeast Asia: Human rights and cultural studies. Asian Studies Review; 37 (3): 335-349.

Ofield Simon (2005) Cruising the archive. Journal of Visual Culture; 4 (3): 351-364.

Phillips Jak (2013) LGBT rights blossom in repressive Vietnam, but no sign of further freedoms. Time, online publication, 31 July, http://world.time.com/2013/07/31/ lgbt-rights-blossom-in-repressive-vietnam-but-no-sign-of-further-freedoms/.

Phinney Harriet M (2008) Objects of affection: Vietnamese discourses on love and emancipation. Positions: East Asia Cultures Critique; 16 (2): 329-358.

Poshyananda Apinan (2000) Positioning contemporary Asian art. Art Journal Spring; 59 (1): 10-13.

Promadhattavedi Chavitchai (1996) Twenty Vietnamese painters: Aspects of contemporary Vietnamese painting In: Cultural Representation in Transition: New Vietnamese Painting. The Siam Society: Bangkok, Thailand, pp 32-37.

Radulovic Veronika (n.d.) Vietnam Archive. Radulovic.org. Online publication, http://www.radulovic.org/wordpress/vietnam/archive/. 
Radulovic Veronika (2009) Everything can happen between now and then... In: Lee Sarah and Nhu Huy Nguyen (eds) Essays on Modern and Contemporary Vietnamese Art. Singapore: Singapore Art Museum, pp 189-197.

Reed Christopher (2011) Art and Homosexuality. Oxford University Press: New York. Robinson Abby (2006) New Vietnamese photography. Online publication, http:// www.ngodinhtruc.com/en/archives/9-archives.html.

Rydstrøm Helle (2006) Sexual desires and "social evils": Young women in rural Vietnam. Gender, Place and Culture; 13 (3): 283-301.

Schuler S, Hoang TA, Vu SH, Tran HM, Bui TTM and Pham VT (2006) Constructions of gender in Vietnam: In pursuit of the "three criteria". Culture, Health \& Sexuality; 8 (5): 383-394.

Scott Phoebe (2015) Parallels and divergence: Curating modern Vietnamese art in a regional context In: Herbelin C, Wisniewski B and Dalex F (eds) Arts du Vietnam. Nouvelles approches. Presses Universitaires de Rennes: Rennes, France, pp 205-215.

Sharbaugh Patrick (2014) Report: There's more censorship circumvention in Vietnam than in any other nation. Online publication, 15 July, http://vietmeme. net/2014/07/15/report-theres-more-censorship-circumvention-in-vietnamthan-in-any-other-nation/.

Sliwinska Basia (2013) Art and queer culture: A peephole into "anything else you want to be". Third Text; 7 (6): 808-810.

Talawas. (2002) Talawas round table 'contemporary Vietnamese art in the international context'. Online publication, http://www.talawas.org/talaDB/ showFile.php? res $=769 \& \mathrm{rb}=0201$.

Taylor N (2012) Defiant abstraction: Nguyen Trung and the modernist movement in South Vietnam from 1965-1990. Association for Asian Studies Annual Conference. Toronto, Canada, 15-18 March.

Taylor N (2014) Nguyen Trung: A Monograph. CUC Gallery: Hanoi, Vietnam.

Taylor NA (2007) Vietnamese anti-art and anti-Vietnamese artists: Experimental performance culture in Ha Noi's alternative exhibition spaces. Journal of Vietnamese Studies; 2 (2): 108-128.

Taylor NA (2009) Art in space: Reflections on the rise of performance art in Vietnam In: Lee Sarah and Nhu Huy Nguyen (eds) Essays on Modern and Contemporary Vietnamese Art. Singapore: Singapore Art Museum, pp 173-180.

Taylor NA (2011) The Southeast Asian art historian as ethnographer? Third Text; 25 (4): 475-488.

Thomas M (2001) Public spaces/public disgraces: Crowds and the state in contemporary Vietnam. Sojourn Journal of Social Issues in Southeast Asia; 16 (2): 306-317.

Tien Van Mieu (n.d.) Tiến Văn Miếu Họa Sĩ Nguyễn Văn Tiến. Online publication, http://www.tienvanmieu.com/vi/.

Tran Ben (2012) Queer Internationalism and modern Vietnamese aesthetics In: Mark Wollaeger and Matt Eatough (eds) The Oxford Handbook on Global Modernisms, online publication, September, 10.1093/oxfordhb/9780195338904.013.0015.
Tran Luong (2009) Running out of fuel right after taking off In: Sarah Lee and Nguyen Nhu Huy (eds) Essays on Modern and Contemporary Vietnamese Art. Singapore: Singapore Art Museum, pp 182-188.

Truong Tan (2010) In the past I was very lonely, in art. Soi.today, online publication, 27 April, http://soi.today/?p $=2687$.

Tsai Sylvia (2014) Open boundaries: Interview with Truong Tan. ArtAsiaPacific, online publication, 26 February: http://artasiapacific.com/Blog/OpenBoundar iesInterviewWithTruongTan.

USAID. (2015) Vietnam HIV/AIDS. Online publication, https://www.usaid.gov/ vietnam/hiv-aids.

Viet Le (2015) In the studio: Viêt Lê. Andofotherthings, online publication 23 December, www.andofotherthings.com /2015/12/23/in-the-studio-viet-le/.

WPP [World Press Photo]. (2013) Maika Elan (2013 World Photo Contest) Online video, 8 July, https://vimeo.com/69886312.

Zhuang Wubin (2010) Post-Doi Moi photography in Saigon: Nguyen Xuan Khanh and Bui Xuan Huy. Asian Art Newspaper, November, 6-8.

Zhuang Wubin (2015) Documenting as method: Photography in Southeast Asia cademia.edu, online publication, https://independent.academia.edu/ZhuangWu bin/Exhibition-Catalogues.

\section{Data availability}

Data sharing is not applicable to this article, as no datasets were generated or analysed during the current study.

\section{Additional information}

Competing interests: The author declares no competing financial interests.

Reprints and permission information is available at http://www.palgrave-journals.com/ pal/authors/rights_and_permissions.html

How to cite this article: Nualart C (2016). Queer art in Vietnam: from closet to pride in two decades. Palgrave Communications. 2:16009 doi: 10.1057/palcomms.2016.9.

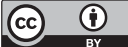

This work is licensed under a Creative Commons Attribution 4.0 International License. The images or other third party material in this article are included in the article's Creative Commons license, unless indicated otherwise in the credit line; if the material is not included under the Creative Commons license, users will need to obtain permission from the license holder to reproduce the material. To view a copy of this license, visit http://creativecommons.org/licenses/by/4.0/ 